\title{
Multicentre phase II studies evaluating imatinib plus hydroxyurea in patients with progressive glioblastoma
}

\section{DA Reardon*,I, G Dresemann ${ }^{2}$, S Taillibert ${ }^{3}$, M Campone ${ }^{4}$, M van den Bent ${ }^{5}$, P Clement ${ }^{6}$, E Blomquist ${ }^{7}$, L Gordower $^{8}$, H Schultz ${ }^{9}$, J Raizer ${ }^{10}$, P Hau ${ }^{11}$, J Easaw ${ }^{12}$, M Gil $^{13}$, J Tonn ${ }^{14}$, A Gijtenbeek ${ }^{15}$, U Schlegel ${ }^{16}$, P Bergstrom ${ }^{17}$, S Green $^{18}$, A Weir ${ }^{18}$ and Z Nikolova ${ }^{18}$}

'The Preston Robert Tisch Brain Tumor Center, Duke University Medical Center, Durham, NC, USA; ${ }^{2}$ Zentrum für Neuro-Onkologie am Ärztehaus Velen, Velen, Germany; ${ }^{3}$ Hopital Pitie Salpétrière, Paris, France; ${ }^{4}$ Centre René Gauducheau, Saint-Herblain, France; ${ }^{5}$ Daniel den Hoed Cancer Center, Erasmus University Hospital, Rotterdam, The Netherlands; ${ }^{6}$ UZ Gasthuisberg, Leuven, Belgium; ${ }^{7}$ Onkologikliniken Akademiska sjukhuset, Uppsala, Sweden; ${ }^{8} \mathrm{CHU}$ Erasme, Brussels, Belgium; ${ }^{9}$ Aarhus University Hospital, Århus, Denmark; ${ }^{10}$ Northwestern University, Feinberg School of Medicine, Northwestern Memorial Hospital, Chicago, IL, USA; "'Klinik und Poliklinik für Neurologie der Universität Regensburg, Universitaetsklinikum Regensburg, Regensburg, Germany; ${ }^{12}$ Tom Baker Cancer Center, Calgary, Alberta, Canada; ${ }^{13}$ Institut Català d'Oncologia, Hospital Durans I Reynals, L'Hospitalet de Llobregat, Barcelona, Spain; ${ }^{14}$ LMU München, München, Germany; ${ }^{15}$ Radboud University Nijmegen Medical Centre, Nijmegen, The Netherlands; ${ }^{16}$ Knappschaftskrankenhaus, Ruhr-University Bochum, Germany; ${ }^{17}$ Onkologikliniken, Norrlands Universitetssjukhus, Umea, Sweden; ${ }^{18}$ Novartis Pharma AG, Basel, Switzerland

BACKGROUND: We evaluated the efficacy of imatinib mesylate in addition to hydroxyurea in patients with recurrent glioblastoma (GBM) who were either on or not on enzyme-inducing anti-epileptic drugs (EIAEDs).

METHODS: A total of 231 patients with GBM at first recurrence from 21 institutions in 10 countries were enrolled. All patients received $500 \mathrm{mg}$ of hydroxyurea twice a day. Imatinib was administered at $600 \mathrm{mg}$ per day for patients not on EIAEDs and at $500 \mathrm{mg}$ twice a day if on EIAEDs. The primary end point was radiographic response rate and secondary end points were safety, progression-free survival at 6 months (PFS-6), and overall survival (OS).

RESULTS: The radiographic response rate after centralised review was 3.4\%. Progression-free survival at 6 months and median OS were $10.6 \%$ and 26.0 weeks, respectively. Outcome did not appear to differ based on EIAED status. The most common grade 3 or greater adverse events were fatigue (7\%), neutropaenia (7\%), and thrombocytopaenia (7\%).

CONCLUSION: Imatinib in addition to hydroxyurea was well tolerated among patients with recurrent GBM but did not show clinically meaningful anti-tumour activity.

British Journal of Cancer (2009) I 01, 1995-2004. doi:I0.1038/sj.bjc.66054II www.bjcancer.com

Published online 10 November 2009

(c) 2009 Cancer Research UK

Keywords: glioblastoma; imatinib mesylate; platelet-derived growth factor; c-KIT

There are currently few effective treatment options available for adults with glioblastoma (GBM), the most common malignant primary brain tumour. Median survival for newly diagnosed GBM is approximately 15 months from diagnosis, after standard therapy of temozolomide (TMZ) and radiotherapy and only $26 \%$ of patients survive 2 years (Stupp et al, 2005). Although recent studies with therapeutics targeting vascular endothelial growth factor (VEGF) have shown encouraging results (Vredenburgh et al, 2007; Friedman et al, 2009), most salvage therapies after progression have proven ineffective, with a median time to progression of only 9 weeks, low response rates and life expectancy of only a few months (Wong et al, 1999; Ballman et al, 2007; Lamborn et al, 2008).

\footnotetext{
* Correspondence: Dr DA Reardon, The Preston Robert Tisch Brain Tumor Center at Duke, Duke University Medical Center, Box 3624, Durham, NC 277I0, USA; E-mail: reard003@mc.duke.edu

Received 18 August 2009; revised 2 October 2009; accepted 9 October 2009; published online 10 November 2009
}

Imatinib mesylate (Glivec or Gleevec), a tyrosine kinase inhibitor of platelet-derived growth factor receptors (PDGFRs) $\alpha$ and $\beta$; c-KIT, the receptor for stem cell factor; c-Fms, the receptor for macrophage-colony stimulating factor; Abl, and Arg $\mathrm{TK}$, is currently approved for several indications including Philadelphia chromosome-positive $(\mathrm{Ph}+)$ chronic myelogenous leukaemia, $\mathrm{Ph}+$ acute lymphoblastic leukaemia, KIT (CD 117)positive, unresectable or metastatic malignant gastrointestinal stromal tumours, and four rare diseases (hypereosinophilic syndrome, dermatofibrosarcoma protuberans, myelodysplastic/ myeloproliferative diseases, and systemic mastocytosis).

Several factors suggest that imatinib may be an active therapeutic for malignant glioma. First, gliomas frequently overexpress PDGF and PDGFRs in an autocrine/paracrine manner (Nister et al, 1988; Hermanson et al, 1992; Guha et al, 1995; Lokker et al, 2002). Second, c-KIT is expressed by many GBM tumours (Went et al, 2004; Joensuu et al, 2005). Third, imatinib inhibits the growth of human GBM cell lines and prolongs survival of nude mice with intracranial GBM cell implants (Kilic et al, 2000), whereas expression of PDGFR and the chemokine CXCL12/SDF-1 (stromal cell-derived factor-1) predict imatinib sensitivity in vitro 
(Hagerstrand et al, 2006). Finally, imatinib can sensitise human GBM cells to ionising radiation (Russell et al, 2003; Holdhoff et al, 2005).

Preclinical evidence suggests that imatinib may enhance chemosensitivity by several possible mechanisms, including decreasing interstitial fluid pressure (Heuchel et al, 1999; Pietras et al, 2001, 2002, 2003; Ostman, 2004), decreasing angiogenesis (Bergers et al, 2003; Dudley et al, 2003; Hwang et al, 2003; Uehara et al, 2003; Apte et al, 2004; Pietras and Hanahan, 2005), and by affecting DNA repair mechanisms (Aloyz et al, 2004), stromal chemokines (Ostman, 2004), and multidrug transporter activity (Houghton et al, 2004; Ozvegy-Laczka et al, 2004). However, the uptake and distribution of imatinib in the brain is limited by P-gp/BCRP-mediated efflux (Dai et al, 2003), suggesting that combination regimens with imatinib may be more effective than imatinib monotherapy. Clinical studies evaluating imatinib as monotherapy in relapsed GBM showed response rates ranging from 3 to $6 \%$ and a progression-free survival at 6 months (PFS-6) rate of 16\% (Wen et al, 2006; Raymond et al, 2008).

Hydroxyurea (HU) has been used in multiagent regimens against GBM, medulloblastoma, and metastatic brain tumours (Levin and Prados, 1992; Geyer et al, 1994; Kyritsis et al, 1996; Kaba et al, 1997; Prados et al, 1998). Hydroxyurea exerts a cellcycle-specific effect during early S-phase, through inhibition of ribonucleotide reductase, thereby blocking DNA synthesis (Kyritsis et al, 1996). Hydroxyurea exhibits rapid absorption from the gastrointestinal tract after oral dosing and readily crosses the blood-brain barrier. Independently conducted, single-institutional clinical studies have noted anti-tumour activity among patients with recurrent grade 3 (Desjardins et al, 2007) and 4 malignant glioma (Dresemann, 2005; Reardon et al, 2005) after treatment with imatinib (400-1000 mg daily) and HU (1000 mg daily). Each of these studies also confirmed that this combination was well tolerated.

Enzyme-inducing anticonvulsant drugs (EIACDs; eg phenytoin, carbamazepine, phosphenytoin, oxcarbamazepine, and phenobarbital) are known to accelerate the metabolism of imatinib, resulting in a shorter plasma-elimination half-life $\left(t_{1 / 2}\right)$ and a lower area under the plasma concentration time curve (AUC) (Reardon et al, 2005; Wen et al, 2006). We sought to further evaluate the efficacy and tolerability of imatinib in addition to HU among patients with recurrent GBM treated on multi-institutional phase II studies depending on the use of EIACDs or not. Specifically, for study H2201, patients were not on EIACDs, whereas study H2202 only included patients on EIACDs. The primary end point was objective overall response rate (ORR); secondary end points were safety, overall survival (OS), and PFS.

\section{PATIENTS AND METHODS}

\section{Study design and treatment}

We conducted two, parallel open-label, multicentre, single-arm, phase II trials. In study H2201, patients were not allowed to be on EIACDs whereas patients were enrolled on study $\mathrm{H} 2202$ if they were on EIACDs. The dose of imatinib differed between the trials to account for the effect of EIACDs on imatinib metabolism (Reardon et al, 2005; Wen et al, 2006): Patients enrolled on study H2201 received $600 \mathrm{mg}$ once a day, whereas those on study $\mathrm{H} 2202$ received $500 \mathrm{mg}$ twice a day. For both trials, patients received $500 \mathrm{mg}$ of $\mathrm{HU}$ twice a day. The studies were identical in all other respects. Medically appropriate efforts were used to maintain study-specific EIACD exposure for patients on each study; however, H2201 patients were deemed off study if they initiated EIACDs and H2202 patients were similarly censored if they discontinued EIACDs.

Patients remained on study unless they withdrew consent, developed tumour progression or unacceptable toxicity. During the first year of treatment, patients were assessed every 4 weeks, changing to every 8 weeks thereafter. The study was designed according to respective national regulations and was approved by local ethical review boards before patient accrual started. All patients provided written informed consent according to local and national regulations.

\section{Patient eligibility}

All patients were required to have institutional histological confirmation of GBM that was at first recurrence after conventional therapy and measurable disease on gadolinium-enhanced MRI. After study entry, centralised review was conducted to confirm histopathology. Satisfactory haematologic (haemoglobin $\geqslant 10$ g per $100 \mathrm{ml}$, absolute neutrophil count $>1500$ cells per litre, platelets $>100000$ cells per litre), biochemical (serum creatinine $<1.5 \mathrm{mg}$ per $100 \mathrm{ml}$, BUN $<25 \mathrm{mg}$ per $100 \mathrm{ml}$; AST and bilirubin $<1.5 \times$ upper limit of normal) and performance status (ECOG score $\leqslant 2$ or Karnofsky $\geqslant 60 \%$ ) parameters were also required.

Key exclusion criteria included peripheral oedema $\geqslant$ grade 2; pulmonary, pericardial or peritoneal effusions of any grade; an excessive risk of an intracranial haemorrhage; major surgery within 2 weeks before study entry; and concurrent warfarin administration.

\section{Patient assessments}

Disease status was assessed using a modified version of the Macdonald criteria (Macdonald et al, 1990), including an increase in corticosteroid dosing, regardless of radiographic or clinical assessment, as a criteria to define progressive disease (PD). Sites performed each assessment, before submitting the data to a central independent review (CIR) team. The CIR team included three radiologists (two reviewers and an adjudicator) as well as a neurooncologist who conducted a two-stage evaluation of each patient assessment. First, steroid and MRI assessments were independently determined and included in the database. Second, the site neurologic assessment was incorporated to provide an overall outcome assessment. Visits were assessed in sequence; older visits could be reviewed, but newer visits could only be seen after completion of the preceding visit. Adjudication occurred if the overall visit conclusion differed between the two radiologists. To minimise bias, all CIR team members were blinded to the patient study identifier, the results of the other reader, and the final outcome of the patient. Final outcome was hidden by presenting data of each time point only after the previous time point had been assessed.

Safety assessments included weekly complete blood counts and monthly chemistry profiles. Treatment was held until any nonhaematologic grade 3 or 4 event resolved to grade $\leqslant 1$, after which the study regimen was resumed with a reduction in daily imatinib dosing by $200 \mathrm{mg}$. If the event recurred, HU was reduced to $500 \mathrm{mg}$ a day. If the event recurred despite these dose modifications, patients were taken off study. The above guidelines were also followed for grade 3 or greater thrombocytopaenia and grade 4 neutropaenia. Myeloid and erythoid growth factors were permitted according to established guidelines.

\section{Tumour biomarker analysis}

Archival tumour samples from either initial diagnosis or after prior therapy failure were analysed at the Duke University Hospital Cell Imaging Laboratory (Durham, NC, USA). Methylguanine methyltransferase (MGMT), PDGFR $\alpha$ and PDGFR $\beta$, phospho-p44/ 42 MAPK, phospho-S6 ribosomal protein, phospho-AKT, PTEN, EGFR, and EGFRvIII were assessed using immunohistochemistry (IHC) reagents and methods (Supplementary Methods). Similarly, dual-colour fluorescent in situ hybridisation (FISH) was 
performed on formalin-fixed, paraffin-embedded tissue specimens using commercially available probes, including EGFR/CEP 7, PTEN/CEP 10 (Vysis, Downers Grove, IL, USA), and c-KIT/CEP 4 for EGFR, PTEN, and c-KIT DNA locus copy number (Supplementary Methods). Genes were classified as polysomic or amplified if their copy number relative to respective centromere probe exceeded 1 or 2 , respectively.

\section{Pharmacokinetic analysis}

Blood samples were collected from a subset of patients on each study on days 6 and 29 before treatment and $0.5,1,2,3,4,8,12,13$, 14 , and $24 \mathrm{~h}$ after their morning dose. For these patients, HU was initiated after the 24-h sample for day 6 was obtained. Plasma supernatants were separated by centrifugation and immediately frozen $\left(-20^{\circ} \mathrm{C}\right)$. The day 29 plasma supernatants were split for both imatinib and $\mathrm{HU}$ analyses. Plasma concentrations of imatinib and its metabolite, CGP74588, were determined by high-pressure liquid chromatography/mass spectrometry (Parise et al, 2003) whereas HU plasma concentrations were measured by gas chromatography and mass spectroscopy. The individual plasma concentration of data for each subject was used to calculate pharmacokinetic parameters according to the model-independent approach using WinNonlin software (Version 5.2; Pharsight Corporation, Mountain View, CA, USA). Nominal sampling times were used for calculating summary statistics of the plasma concentration data.

\section{Statistical considerations}

A total of 220 adult patients (110 in each study) were planned to enroll. Wong et al (1999) previously reported a 5\% radiographic response rate among patients with GBM treated with TMZ at first recurrence. In the current studies, 110 patients were estimated as required per study to provide a $95 \%$, two-sided confidence interval for radiographic response to have a lower limit of $5 \%$, including a $10 \%$ expected dropout rate.

An interim analysis was performed after 101 patients were enrolled in both studies combined. Accrual continued until a data cut-off occurred 4 months after the 101st patient had been enrolled to allow for at least 16 weeks of treatment. At the interim analysis, if there were $\leqslant 4$ responses (CR or PR) observed from 101 patients, both studies were to be terminated due to lack of efficacy. If the studies continued, combination therapy was to be declared as having insufficient activity if there were $\leqslant 15$ responses observed from the 220 patients to be recruited.

A log-rank test was used to compare the OS and PFS experience of patient subgroups defined by various biomarkers. Patients with inadequate samples to analyse for a particular marker were excluded from that specific statistical analysis. Within subgroups, the Kaplan-Meier estimator was used to generate estimates of median OS and PFS, as well as 6-, 12-, and 24-month OS and PFS rates.

\section{RESULTS}

\section{Patient characteristics}

The intent-to-treat (ITT) population consisted of 231 enrolled patients including 131 on study $\mathrm{H} 2201$ and 100 on study $\mathrm{H} 2202$. Study H2201 accrued more rapidly, hence a higher percentage of eligible patients were not on EIACDs. Otherwise, characteristics of patients accrued to both studies were comparable (Table 1). Adequate tumour material for central histopathology review was available from 177 patients (77.7\%) and confirmed GBM in 158 cases $(89.3 \%)$. This rate is comparable to that previously reported in other multi-institutional studies (Stupp et al, 2005; Raymond et al, 2008). The remaining patients had either grade 3 malignant glioma $(n=11,7.0 \%)$, grade 2 glioma $(n=2,1.3 \%)$, or were nondiagnostic $(n=6,3.8 \%)$. Most patients $(88.7 \%)$ had just one measurable lesion at baseline. Only $11.7 \%$ of patients had additional lesions documented for evaluation, which were too small to measure ('evaluable lesions'). According to the CIR, 9 patients (3.9\%) had only evaluable lesions at their baseline MRI scan. Thirty-three patients (14\%) enrolled within 3 months of XRT/daily TMZ completion; however, outcome among this subset did not differ compared to the remaining patients (data not shown)

Table I Patient characteristics at enrolment (ITT population)

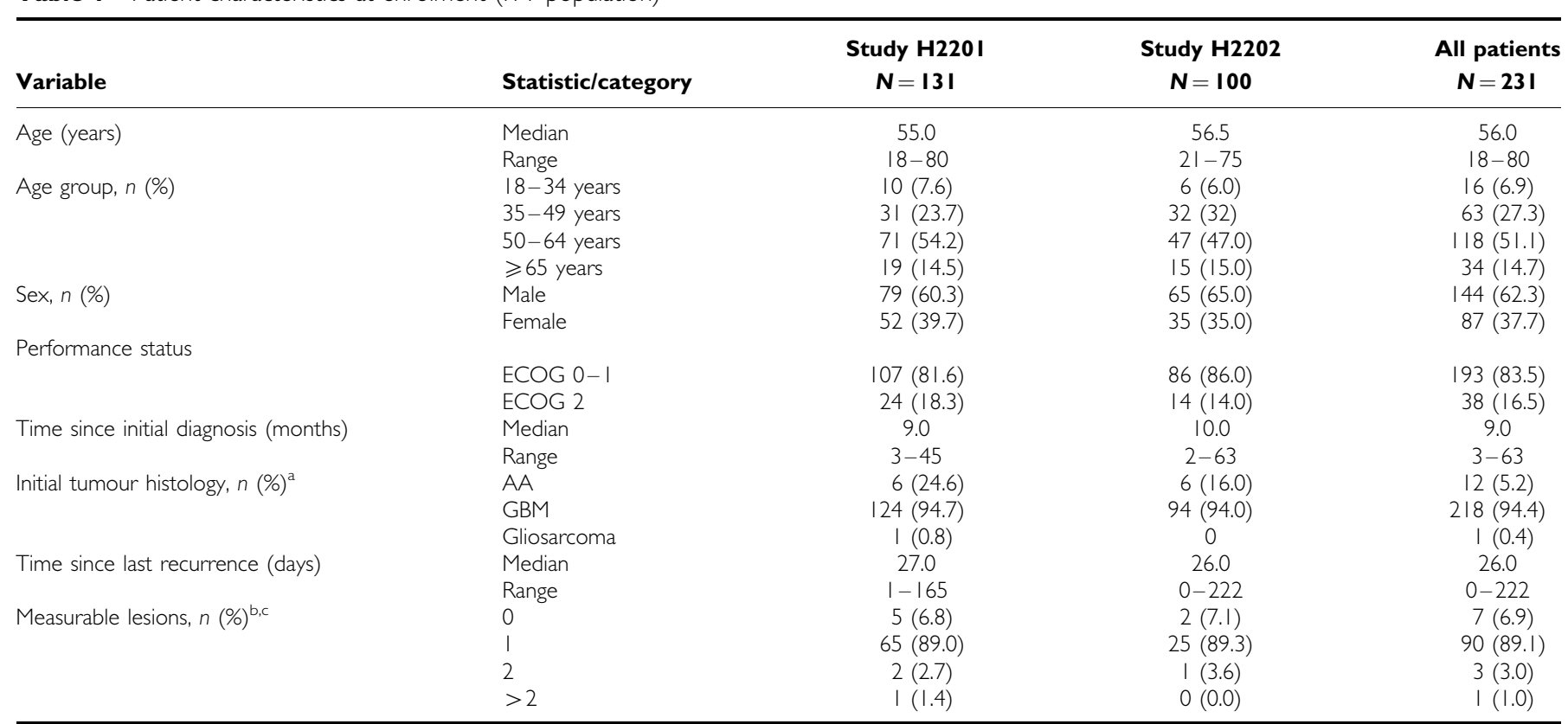

\footnotetext{
${ }^{a}$ All patients must have independent histological confirmation of their diagnosis as part of their inclusion. This review is still ongoing at the time of the interim analysis. ${ }^{\mathrm{b}}$ Tumour burden measurements are based on central independent review (CIR) data. ${ }^{\mathrm{C}}$ Tumour assessment information was assigned at baseline assessment (first MRI scan). All other data were collected at screening (in some cases this equalled baseline).
} 
indicating that enrolment of patients with possible pseudoprogression (Brandes et al, 2008; Brandsma et al, 2008) did not influence the outcome of this study. No patients had to discontinue study participation due to changing enzyme-inducing antiepileptic drug (EIAED) status.

\section{Toxicity}

The median times on study were 6 weeks (range, 1.3-91 weeks) and 4 weeks (range, $0.1-102$ weeks) for study H2201 and H2202, respectively. A total of 195 patients $(84.8 \%)$ received less than 180 days of therapy whereas 20 patients $(8.7 \%)$ and 15 patients $(6.5 \%)$ remained on study for $180-365$ days and $>365$ days, respectively.

The adverse events seen in the study were as expected for this population and these agents. In general, they were mild and transient (Table 2). There were no major differences in adverse events between the two studies. Dose adjustment or interruption due to adverse events affected $34 \%$ of $\mathrm{H} 2201$ patients and $39 \%$ of $\mathrm{H} 2202$ patients. Patients on each study (8\%) discontinued therapy due to toxicity. Among grade 3 or higher events, the most common included fatigue (7.0\%), neutropaenia (6.9\%), and thrombocytopaenia $(6.9 \%)$. There were no grade 5 attributable to adverse events.

Table 2 Adverse events in at least 10\% of patients (Safety population)

\begin{tabular}{|c|c|c|c|}
\hline Adverse event & $\begin{array}{c}\text { Study H220 I } \\
\begin{array}{c}N=|3| \\
n(\%)\end{array}\end{array}$ & $\begin{array}{c}\text { Study H2202 } \\
\begin{array}{c}\mathbf{N}=99 \\
n(\%)\end{array}\end{array}$ & $\begin{array}{c}\text { All patients } \\
\begin{array}{c}N=\mathbf{2 3 0} \\
n(\%)\end{array}\end{array}$ \\
\hline \multicolumn{4}{|l|}{ Nausea } \\
\hline Grade 3 & 0 & $2(2.0)$ & $2(0.9)$ \\
\hline Grade 4 & 0 & 0 & 0 \\
\hline All grades & $50(38.2)$ & $39(39.4)$ & 89 (38.7) \\
\hline \multicolumn{4}{|l|}{ Fatigue } \\
\hline Grade 3 & $7(5.3)$ & $6(6.1)$ & $13(5.7)$ \\
\hline Grade 4 & $3(2.3)$ & 0 & $3(1.3)$ \\
\hline All grades & $41(31.3)$ & $37(37.4)$ & $78(33.9)$ \\
\hline \multicolumn{4}{|l|}{ Peripheral oedema } \\
\hline Grade 3 & I (0.8) & $2(2.0)$ & $3(1.3)$ \\
\hline Grade 4 & 0 & 0 & 0 \\
\hline All grades & 31 (23.7) & $24(24.2)$ & $55(23.9)$ \\
\hline \multicolumn{4}{|l|}{ Diarrhoea } \\
\hline Grade 3 & 0 & I (I.0) & I (0.4) \\
\hline Grade 4 & 0 & 0 & 0 \\
\hline All grades & $27(20.6)$ & $16(16.2)$ & $43(18.7)$ \\
\hline \multicolumn{4}{|l|}{ Thrombocytopaenia } \\
\hline Grade 3 & $8(6.1)$ & $2(2.0)$ & $10(4.3)$ \\
\hline Grade 4 & $4(3.1)$ & $2(2.0)$ & $6(2.6)$ \\
\hline All grades & $23(17.6)$ & II (II.I) & $34(14.8)$ \\
\hline \multicolumn{4}{|l|}{ Anaemia } \\
\hline Grade 3 & $5(3.8)$ & 0 & $5(2.2)$ \\
\hline Grade 4 & 0 & 0 & 0 \\
\hline All grades & $21(16.0)$ & II (II.I) & $32(13.9)$ \\
\hline \multicolumn{4}{|l|}{ Constipation } \\
\hline Grade 3 & 0 & I (1.0) & I (0.4) \\
\hline Grade 4 & 0 & 0 & 0 \\
\hline All grades & $22(16.8)$ & $10(10.1)$ & $32(13.9)$ \\
\hline \multicolumn{4}{|l|}{ Rash } \\
\hline Grade 3 & 0 & 0 & 0 \\
\hline Grade 4 & 0 & 0 & 0 \\
\hline All grades & $14(10.7)$ & $13(13.1)$ & $27(11.7)$ \\
\hline
\end{tabular}

\section{Pharmacokinetic analyses}

Population PK samples were obtained from 15 patients on study H2201 and 6 patients on study H2202. Overall, imatinib, CGP74588, and HU pharmacokinetic results were consistent with those previously reported and confirm the marked impact of EIAEDs on imatinib metabolism (Table 3; Reardon et al, 2005). Specifically, dose-normalised Cmax and AUCs of imatinib were lowered for patients on EIAEDs compared with those who were not on EIAEDs. Slight elevations of CGP74588 compared with parent drug ratio were noted for patients on EIAEDs (0.23 vs 0.19$)$ or not receiving EIAEDs $(0.41$ vs 0.35$)$ in the presence of HU. Imatinib exposure on day 29 (with HU) was slightly increased compared with day 6 (imatinib alone) for patients on study H2201, but was slightly decreased for patients on study H2202, although these differences did not achieve statistical significance. The exposure and elimination of $\mathrm{HU}$ were not different between patients receiving or not receiving EIAEDs.

\section{Tumour biomarker analysis}

Table 4 summarises the number of patients who had sufficient archival tumour material available for biomarker analysis by IHC and FISH, as well as the association of marker expression with outcome. Of note, 80 of 91 (88\%) assessable tumours were positive for PDGFR $\alpha$, whereas 47 of 67 (70\%) assessable tumours expressed PDGFR $\beta$. Among 25 tumours that were assessable for c-KIT copy number analysis by FISH, $1(4 \%)$ had evidence of gene amplification (Figure 1) and 1 (4\%) was polysomic.

\section{Outcome}

Table 5 shows the study analysis populations. The safety population was one less than the ITT population because one patient was lost to follow-up immediately after baseline assessments. At the time of data analysis, most patients were off study with disease progression or death (82\%), whereas adverse events, withdrawal of consent, completion of planned therapy, and miscellaneous factors accounted for $8,5,3$, and $3 \%$ of study discontinuations, respectively.

Overall, five patients on study $\mathrm{H} 2201$ (3.8\%) and three on study H2202 (3\%) achieved either a PR or CR confirmed by the CIR giving an ORR of $3.4 \%$ (Table 5). In addition, $19 \%$ of patients on each study achieved stable disease (SD). Of note, 13 patients $(5.6 \%)$ were classified as CR or PR by local investigators, but were not confirmed by the CIR. Nineteen patients $(8.2 \%)$ had either a confirmed CR or PR, or achieved SD lasting 6 months or more. With one confirmed responder and three unconfirmed responders at the interim analysis, a lack of efficacy for the drug combination was concluded as per the statistical design, and the trial was closed for accrual. However, accrual was sufficiently robust in the interval between enrolment of the 101st patient and completion of the interim analysis that study $\mathrm{H} 2201$ actually over-accrued, and study H2202 accrued 100 of the planned 110 patients.

Progression-free survival rates at 6 months were $11.2 \%$ (95\% CI, 5.7-16.6) for study $\mathrm{H} 2201$ and $9.9 \%$ (95\% CI, 3.8-15.9) for study H2202 (Table 5; Figure 2A). Progressive disease was defined by MRI assessment in 114 patients (51.6\%), whereas 41 patients $(18.6 \%)$ were defined as progressive by increased corticosteroid use only and 26 patients $(11.8 \%)$ solely by neurologic decline. Forty patients $(18.1 \%)$ died, without previous PD determination, presumably due to PD. Median OS was 25.3 weeks (95\% CI, 19.933.0) for study $\mathrm{H} 2201$ and 27.1 weeks (95\% CI, 19.9-39.1) for study H2202 (Table 4; Figure 2B).

None of the tumour markers assessed by IHC among archival tumour material obtained from patients correlated with PFS (Table 4). However, single patients with either c-KIT amplification or polysomy remained progression-free for 290 and 232 days, 
Table 4 Tumour marker analysis and progression-free survival

\begin{tabular}{|c|c|c|c|c|c|}
\hline Variable & Result & $\begin{array}{l}\text { Number of } \\
\text { patients }\end{array}$ & Median & $95 \% \mathrm{Cl}$ & $P$-value \\
\hline \multicolumn{6}{|c|}{ Immunohistochemistry } \\
\hline \multirow[t]{2}{*}{ MGMT } & Positive & 25 & 37.0 & $28.0,75.0$ & \multirow[t]{2}{*}{0.68} \\
\hline & Negative & 62 & 49.0 & $30.0,55.0$ & \\
\hline \multirow[t]{2}{*}{ EGFR } & Positive & 52 & 50.0 & $29.0,55.0$ & \multirow[t]{2}{*}{0.083} \\
\hline & Negative & 2 & 26.0 & $99.0,43.0$ & \\
\hline \multirow[t]{2}{*}{ EGFRvIII } & Positive & 17 & 49.0 & $29.0,57.0$ & \multirow[t]{2}{*}{0.863} \\
\hline & Negative & 73 & 50.0 & $30.0,55.0$ & \\
\hline \multirow[t]{2}{*}{ PTEN } & Positive & 27 & 54.0 & $28.0,62.0$ & \multirow[t]{2}{*}{0.88} \\
\hline & Negative & 54 & 39.0 & $30.0,54.0$ & \\
\hline \multirow[t]{2}{*}{56} & Positive & 13 & 54.0 & $28.0,56.0$ & \multirow[t]{2}{*}{0.579} \\
\hline & Negative & 5 & 49.0 & $9.0,57.0$ & \\
\hline \multirow[t]{2}{*}{ MAPK } & Positive & 27 & 31.0 & $29.0,54.0$ & \multirow[t]{2}{*}{0.467} \\
\hline & Negative & 10 & 41.0 & $28.0,56.0$ & \\
\hline \multirow[t]{2}{*}{ AKT } & Positive & 24 & 43.0 & $29.0,55.0$ & \multirow[t]{2}{*}{0.983} \\
\hline & Negative & 16 & 31.0 & $29.0,57.0$ & \\
\hline \multirow[t]{2}{*}{ VEGF } & Positive & 39 & 39.0 & $29.0,55.0$ & \multirow[t]{2}{*}{0.409} \\
\hline & Negative & 25 & 55.0 & $50.0,83.0$ & \\
\hline \multirow[t]{2}{*}{ PDGFR $\alpha$} & Positive & 80 & 49.0 & $31,55.0$ & \multirow[t]{2}{*}{0.26} \\
\hline & Negative & 11 & 55.0 & $28.0,232.0$ & \\
\hline \multirow[t]{2}{*}{ PDGFR $\beta$} & Positive & 47 & 55.0 & $37.0,57.0$ & \multirow[t]{2}{*}{0.192} \\
\hline & Negative & 20 & 43.0 & $29.0,55.0$ & \\
\hline \multicolumn{6}{|c|}{ Fluorescence in situ hybridisation } \\
\hline \multirow[t]{2}{*}{ EGFR } & Increased & 13 & 57.0 & $49.0,112.0$ & \multirow[t]{2}{*}{0.802} \\
\hline & Normal & 19 & 54.0 & $29.0,83.0$ & \\
\hline \multirow[t]{2}{*}{ PTEN } & Deleted & 7 & 54.0 & $29.0,135.0$ & \multirow[t]{2}{*}{0.804} \\
\hline & Normal & 18 & 55.0 & $43.0,83.0$ & \\
\hline \multirow[t]{2}{*}{$c-K I T$} & Increased & 2 & 261.0 & $232.0,290.0$ & \multirow[t]{2}{*}{0.021} \\
\hline & Normal & 23 & 54.0 & $43.0,75.0$ & \\
\hline
\end{tabular}

Abbreviations: MGMT = methylguanine methyltransferase; PDGFR = platelet-derived growth factor receptor; $\mathrm{VEGF}=$ vascular endothelial growth factor.

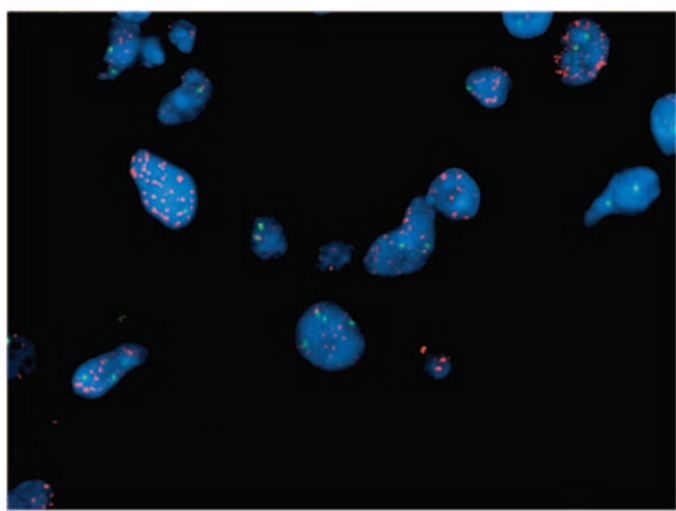

Figure I Representative example of c-KIT gene amplification detected by fluorescence in situ hybridisation (FISH). High-level amplification of c-KIT (red signals) detected along with two copies of chromosome 4 centromeres (green signals).

respectively. Compared with patients with normal c-KIT copy number $(n=23)$, PFS was increased among those with either c-KIT polysomy or amplification $(P=0.021)$. 
Table 5 Patient outcome

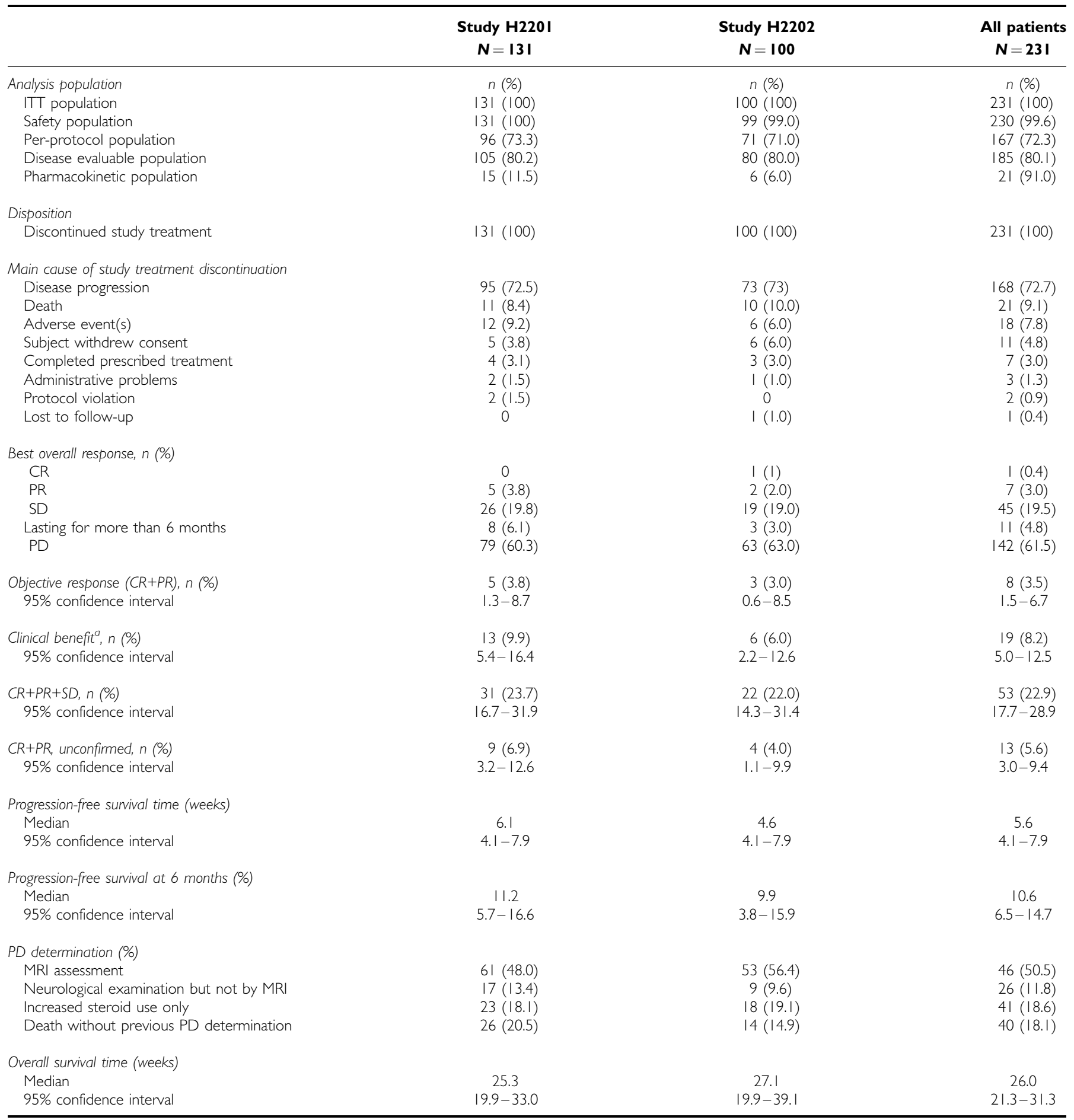

Abbreviations: $\mathrm{CIR}=$ centralised independent review; $C R=$ complete response; $I T=$ intent-to-treat; $P D=$ progressive disease; $P R=$ partial response; $S D=$ stable disease. ITT population = Patients who received at least one dose of any of the two study drugs (imatinib, HU). Safety population= Patients from the ITT population who had at least one post-baseline safety assessment. Disease evaluable population = Patients in the ITT population without major protocol deviation. Per-protocol population $=$ Patients in the ITT population with at least 25 days of treatment with either study drug, with a baseline MRI scan, with a post-baseline MRI scan or a record of death or progression, and without major protocol deviation. Patients alive and without progression were considered as censored at time of last available tumour assessment. Progression-free survival time percentiles and rates were calculated by Kaplan-Meier method. ${ }^{a}$ Clinical benefit was defined as objective response or as SD lasting for $>6$ months from start of treatment.

\section{DISCUSSION}

Two prior, single-institutional studies independently suggested that the combination of imatinib and HU had anti-tumour activity among patients with recurrent GBM. Dresemann (2005) first reported that 6 of 30 patients $(20 \%)$ achieved a radiographic response whereas 11 additional patients $(37 \%)$ achieved SD for a median of 6 months (range 3-32 months). In a follow-up phase II study among 33 patients, Reardon et al (2005) noted a radiographic response rate of $9 \%$ and PFS- 6 of $27 \%$. The current phase II studies 
A

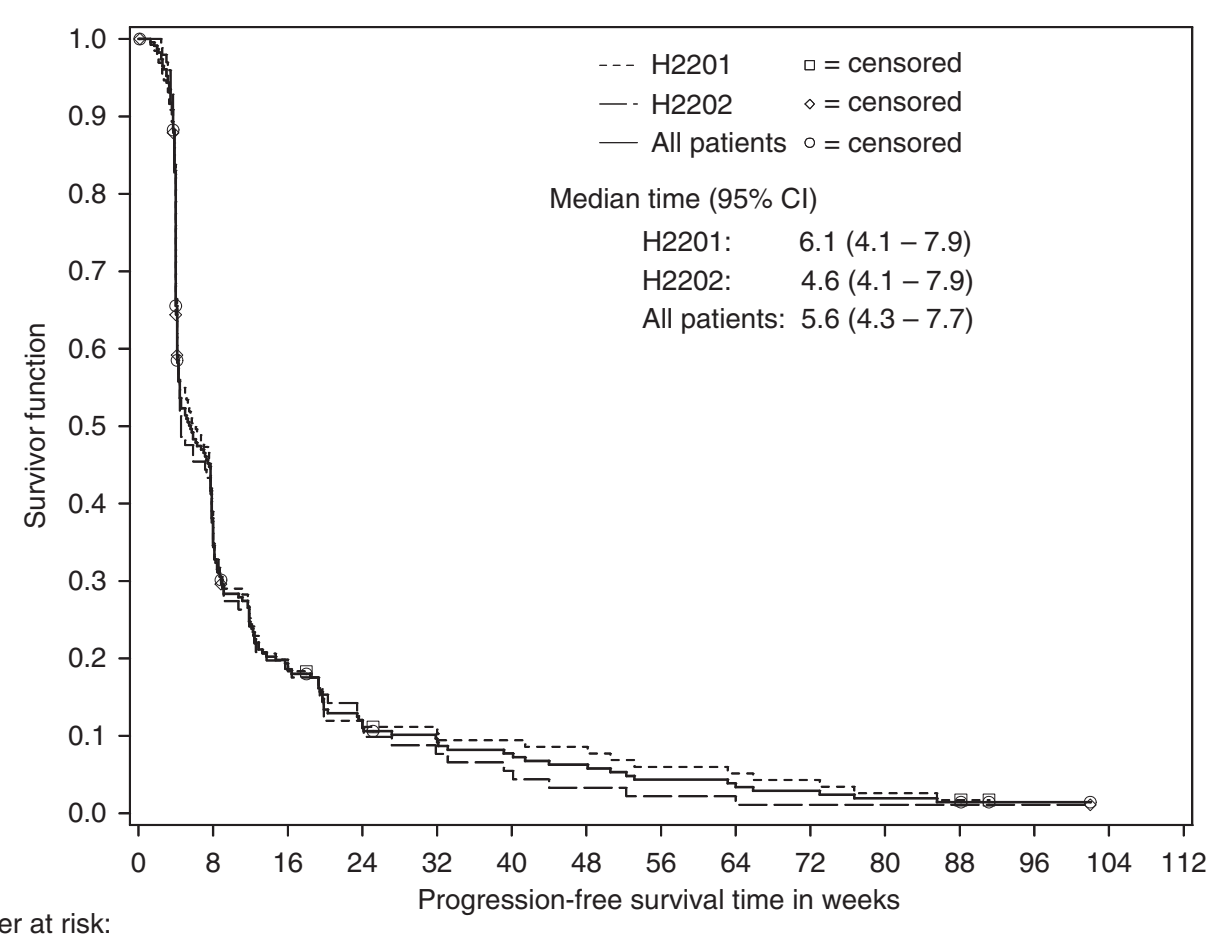

Number at risk:

$\begin{array}{ccccccccccccccc}\text { H2201 } & 131 & 51 & 26 & 15 & 13 & 11 & 10 & 7 & 6 & 5 & 3 & 2 & 0 & 0 \\ \text { H2202 } & 100 & 35 & 17 & 11 & 7 & 5 & 3 & 2 & 2 & 1 & 1 & 1 & 1 & 0 \\ \text { All patients } & 231 & 86 & 43 & 26 & 20 & 16 & 13 & 9 & 8 & 6 & 4 & 3 & 1 & 0\end{array}$

B
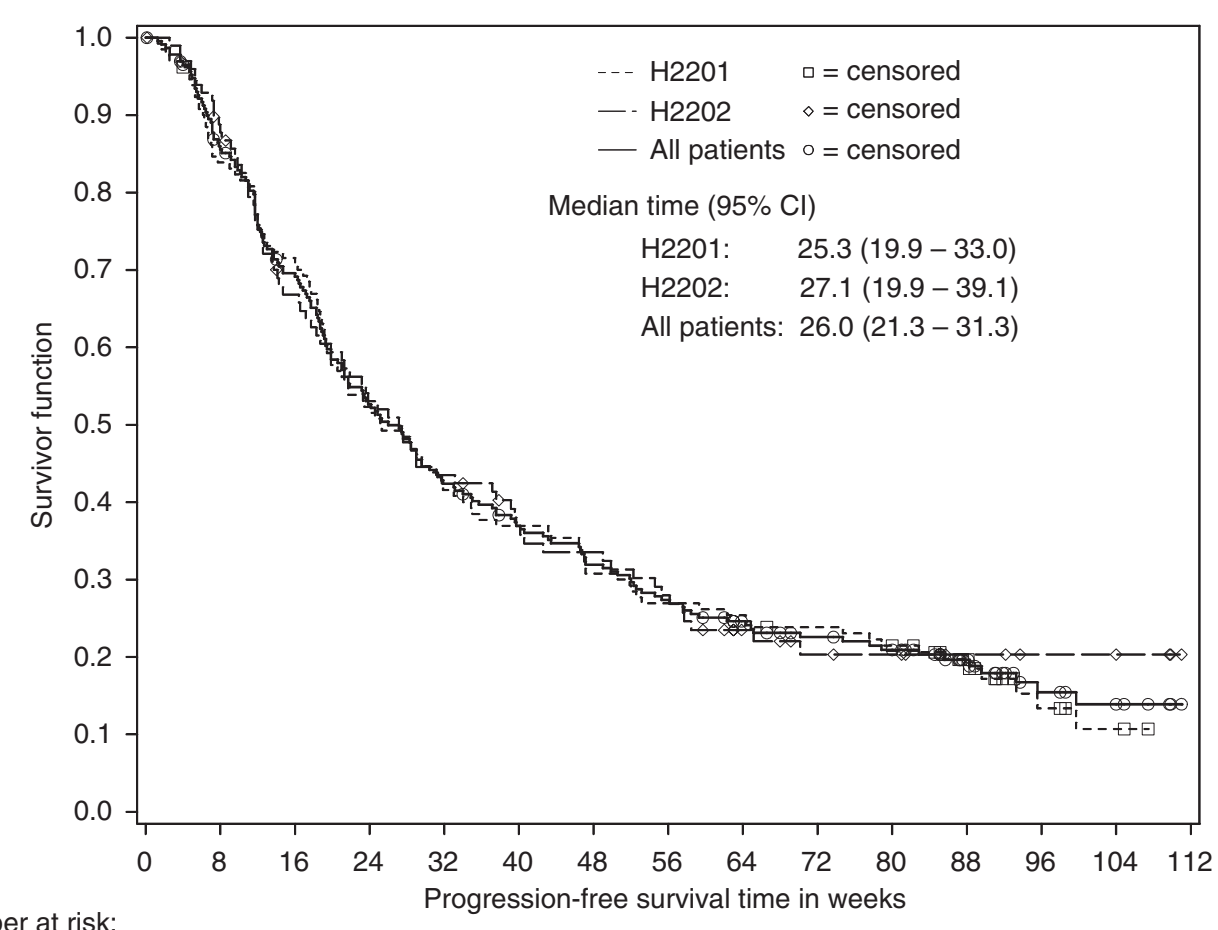

Number at risk:

$\begin{array}{cccccccccccccccc}\text { H2201 } & 131 & 109 & 93 & 68 & 54 & 48 & 40 & 35 & 33 & 30 & 27 & 18 & 7 & 4 & 0 \\ \text { H2202 } & 100 & 86 & 63 & 50 & 41 & 33 & 30 & 25 & 16 & 12 & 11 & 7 & 5 & 5 & 1 \\ \text { All patients } & 231 & 195 & 156 & 118 & 95 & 81 & 70 & 60 & 49 & 42 & 38 & 25 & 12 & 9 & 3\end{array}$

Figure 2 Kaplan-Meier plots of progression-free survival (A) and overall survival (B) for patients enrolled on H22OI and H22O2 studies.

were conducted to further evaluate imatinib in addition to $\mathrm{HU}$ in a multi-institutional setting. If the current multi-institutional studies achieved evidence of anti-tumour benefit comparable to that observed in the two prior single-institutional studies, a randomised, multicentre phase III study comparing imatinib in addition to $\mathrm{HU}$ to alternative salvage therapy was anticipated. 
Toxicity in the current studies was similar to that reported previously confirming that imatinib in addition to $\mathrm{HU}$ is well tolerated among patients with recurrent GBM. The most common toxicities were haematologic and included neutropaenia (grade 3 , $n=12,5 \%$; grade $4, n=5,1.7 \%$ ) and thrombocytopaenia (grade 3 , $n=10,4 \%$; grade $4, n=6,3 \%)$. The most common nonhaematologic toxicities included nausea (39\%), fatigue $(34 \%)$, peripheral oedema $(24 \%)$, and diarrhoea (19\%), although the majority of these events were grade 2 .

Outcome on the current studies was poorer than noted on the prior single-institutional studies, and the trials were closed after the interim analysis. Specifically, only $3.4 \%$ of patients achieved a confirmed radiographic response, and the PFS- 6 was only $10.6 \%$. Of note, we did not observe a significantly different outcome among patients treated on the study H2201 and H2202 trials. Several factors may have contributed to the discrepancy in outcome between the current multicentre studies and the previously reported single-institutional studies. First, single-centre studies may bias towards enrolment of more favourable patients. Approximately $28 \%$ of patients in the current studies received less than 25 days of treatment, typically progressing or dying within this 25-day period. Such patients probably had a poor prognosis and rapid disease advancement on entry to the trial, such that receipt of treatment may have been too late to control disease. In contrast, none of the patients reported by Reardon et al (2005) discontinued therapy prematurely due to rapidly progressive tumour. Imatinib achieves plasma steady-state concentrations after approximately 6 days, but additional time to achieve stable concentrations within the brain is likely required among patients with GBM due to the impact of the blood-brain barrier.

Second, incorporation of rigorous independent, blinded, centralised outcome review with strict assessment guidelines in the current studies may have impacted the rates of determined response (Dodd et al, 2008). In contrast, responses were assessed solely by study investigators in the prior single-centre studies.

Third, this study included an increase in corticosteroid dosing, independent of clinical status and radiologic findings, to define $\mathrm{PD}$. The Macdonald criteria define PD based on ' $\geqslant 25 \%$ increase in size of enhancing tumour or any new tumour on CT or MRI scans, or neurologically worse, and steroids stable or increased.' In fact, the original publication stated, 'Patients requiring escalating steroid doses to maintain neurologic function, in the absence of significant CT worsening (ie, $<25 \%$ increase or no change) may have early tumor progression but are included in stable category'. Indeed, many clinicians do not interpret an increase in corticosteroids to be a sufficient 'stand-alone' criteria for defining PD because clear-cut guidelines to specify when an increase in corticosteroid dosing is appropriate for patients with primary brain tumour are not defined, and no cut-off has been specified for what change in dosage determines a meaningful 'dose increase'. Furthermore, corticosteroids are routinely prescribed to patients with primary brain tumour to improve neurologic deterioration or alleviate increased cerebral oedema due to several factors independent of underlying tumour status, including overly aggressive corticosteroid tapering, seizures, post-operative sequellae, infection, metabolic disturbances, and vascular events. In general, though the decision to increase corticosteroids is individually made by the treating physician based on either worsened neurologic symptoms or radiographic findings such as increased oedema. Nonetheless, in the absence of co-morbid events or changes due to concurrent medications, the need for increased corticosteroids to treat neurologic deterioration is usually due to progressive tumour. Moreover, increasing steroid dosage may mask both clinical deterioration and increased enhancement qualifying for progression. We therefore chose to include this parameter in this study to increase the rigour of PD assessment.
Biologic factors underlying response to imatinib are not well characterised among patients with malignant glioma. In preclinical GBM studies, PDGFR and CXCL12/SDF-1 expression are associated with imatinib sensitivity (Hagerstrand et al, 2006). Although expression of CXCL12/SDF-1 was not assessed in this study, IHC expression of PDGFR did not correlate with PFS. However, we noted statistically increased PFS among two patients with either c-KIT gene amplification or polysomy compared with patients with normal c-KIT copy number. Clearly, these results must be interpreted cautiously due to the small number of patients. However, to further investigate this potential association, we evaluated c-KIT copy number among patients with available archival tumour material who were treated on a previously published phase 2 study (Reardon et al, 2005). Specifically, among 12 patients with adequate tumour material available for analysis, 3 had c-KIT polysomy or gene amplification. Although the differences did not reach statistical significance $(P=0.15)$, the median PFS and PFS-6 were 16.7 weeks (95\% CI, 8.3-130.3) and $40 \%(95 \% \mathrm{CI}, 5.2-75.3 \%)$ for patients with increased c-KIT copy number compared with 8.5 weeks $(95 \% \mathrm{CI}, 7.9-16.1)$ and $10 \%$ (95\% CI, $0.6-35.8$ ) for those with normal copy number. Future studies to evaluate c-KIT gene copy number or protein expression as a biomarker of response to imatinib therapy in patients with recurrent GBM may be warranted.

Of note, Dresemann et al (2008) recently reported preliminary results of a clinical trial in which patients with recurrent GBM were randomised to receive either imatinib and HU vs HU alone. This study noted an overall PFS- 6 of $6 \%$ and no difference in median or OS between the two study arms. This is the only study to date to evaluate HU monotherapy for recurrent GBM and suggests that the activity associated with the regimen of imatinib and $\mathrm{HU}$ may be primarily related to $\mathrm{HU}$.

Despite the previous single-institutional studies showing that imatinib in addition to HU has modest anti-tumour benefit for patients with recurrent GBM, this regimen had no significant activity in this multi-institutional study that incorporated blinded CIR. The decision to include an increase in corticosteroids as an isolated criterion to define $\mathrm{PD}$ in this study remains controversial. Finally, our observation that increased c-KIT copy number may be associated with better outcome suggests that further investigation of the potential prognostic and predictive value of c-KIT may be warranted.

\section{ACKNOWLEDGEMENTS}

This paper has been submitted on behalf of all investigators and colleagues involved in the STi571 H2201 and H2202 studies. We are grateful to the following colleagues who agreed to act as investigators on the trial: Mason W, Princess Margaret Hospital, Toronto, Canada; Stupp R, Hospices/Centre Hospitalier Universitaire Vaudois, Lausanne, Switzerland; Bogdahn U, Universitätsklinikum Regensburg, Regensburg, Germany; Hansen S, Odense Universitets Hospital, Odense C, Denmark; Perez Segura P, Hospital Clinico San Carlos, Madrid, Spain; Licklater J, Royal Brisbane Hospital, Herston, Australia; Le Coutre P, VirchowKlinikum, Berlin, Germany; Weller M, Universitaet Tuebingen, Tuebingen, Germany. In addition to the above investigators, we thank Richard Parker, Novartis Pharma Basel, for excellent trial leadership support; Professor JM Kros and colleagues, Erasmus MC University Hospital/Daniel den Hoed Oncology Center, Rotterdam, The Netherlands, for coordinating the central pathology review; Dr Karl Herholz, Wolfson Molecular Imaging Centre, University of Manchester, England, for coordinating the Central PET scan review; Dr Roger McLendon and colleagues, Duke University Hospital Cell Imaging Laboratory, Durham, NC, USA, for performing the tumour biomarker analysis and $\mathrm{Dr}$ Greg 
Sorensen, Massachusetts General Hospital, Boston, USA, for coordinating the Central Imaging Review team.

\section{REFERENCES}

Aloyz R, Grzywacz K, Xu ZY, Loignon M, Alaoui-Jamali MA, Panasci L (2004) Imatinib sensitizes CLL lymphocytes to chlorambucil. Leukemia 18: $409-414$

Apte SM, Fan D, Killion JJ, Fidler IJ (2004) Targeting the platelet-derived growth factor receptor in antivascular therapy for human ovarian carcinoma. Clin Cancer Res 10: 897-908

Ballman KV, Buckner JC, Brown PD, Giannini C, Flynn PJ, LaPlant BR, Jaeckle KA (2007) The relationship between six-month progression-free survival and 12-month overall survival end points for phase II trials in patients with glioblastoma multiforme. Neuro Oncol 9: 29-38

Bergers G, Song S, Meyer-Morse N, Bergsland E, Hanahan D (2003) Benefits of targeting both pericytes and endothelial cells in the tumor vasculature with kinase inhibitors. J Clin Invest 111: 1287-1295

Brandes AA, Tosoni A, Spagnolli F, Frezza G, Leonardi M, Calbucci F, Franceschi E (2008) Disease progression or pseudoprogression after concomitant radiochemotherapy treatment: pitfalls in neurooncology. Neuro Oncol 10: $361-367$

Brandsma D, Stalpers L, Taal W, Sminia P, van den Bent MJ (2008) Clinical features, mechanisms, and management of pseudoprogression in malignant gliomas. Lancet Oncol 9: 453-461

Dai H, Marbach P, Lemaire M, Hayes M, Elmquist WF (2003) Distribution of STI-571 to the brain is limited by P-glycoprotein-mediated efflux. J Pharmacol Exp Ther 304: 1085-1092

Desjardins A, Quinn JA, Vredenburgh JJ, Sathornsumetee S, Friedman AH, Herndon JE, McLendon RE, Provenzale JM, Rich JN, Sampson JH, Gururangan S, Dowell JM, Salvado A, Friedman HS, Reardon DA (2007) Phase II study of imatinib mesylate and hydroxyurea for recurrent grade III malignant gliomas. J Neurooncol 83: 53-60

Dodd LE, Korn EL, Freidlin B, Jaffe CC, Rubinstein LV, Dancey J, Mooney MM (2008) Blinded independent central review of progression-free survival in phase III clinical trials: important design element or unnecessary expense? J Clin Oncol 26: 3791-3796

Dresemann G (2005) Imatinib and hydroxyurea in pretreated progressive glioblastoma multiforme: a patient series. Ann Oncol 16: 1702-1708

Dresemann G, Weller M, Bogdahn U, Schleyer E, Hosius C, Nikolova Z, Parker R, Kliniken C (2008) Imatinib plus hydroxyurea versus hydroxyurea monotherapy in progressive glioblastoma - An international multicenter, open-label, radomized phase III study (ambrosiastudy). In 13th Annual Meeting of the Society for Neuro-Oncology Yung, A (ed), Vol. 10, pp. 820. Duke University Press: Las Vegas, NV

Dudley A, Gilbert RE, Thomas D, Cox A, Price JT, Best J, Jenkins A (2003) STI-571 inhibits in vitro angiogenesis. Biochem Biophys Res Commun 310: $135-142$

Friedman HS, Prados MD, Wen PY, Mikkelsen T, Schiff D, Abrey LE, Yung WK, Paleologos N, Nicholoas MK, Jensen R, Vredenburgh J, Huang J, Zheng M, Cloughesty T (2009) Bevacizumab along and in combination with irinotecan in recurrent glioblastoma. J Clin Oncol 27: $4733-4740$

Geyer JR, Zeltzer PM, Boyett JM, Rorke LB, Stanley P, Albright AL, Wisoff JH, Milstein JM, Allen JC, Finlay JL, Ayers GD, Shurin SB, Stevens KR, Bleyer WA (1994) Survival of infants with primitive neuroectodermal tumors or malignant ependymomas of the CNS treated with eight drugs in 1 day: a report from the Childrens Cancer Group. J Clin Oncol 12: $1607-1615$

Guha A, Dashner K, Black PM, Wagner JA, Stiles CD (1995) Expression of PDGF and PDGF receptors in human astrocytoma operation specimens supports the existence of an autocrine loop. Int J Cancer 60: $168-173$

Hagerstrand D, Hesselager G, Achterberg S, Wickenberg Bolin U, Kowanetz M, Kastemar M, Heldin CH, Isaksson A, Nister M, Ostman A (2006) Characterization of an imatinib-sensitive subset of high-grade human glioma cultures. Oncogene 25: 4913-4922

Hermanson $M$, Funa $K$, Hartman $M$, Claesson-Welsh L, Heldin $\mathrm{CH}$, Westermark B, Nister M (1992) Platelet-derived growth factor and its receptors in human glioma tissue: expression of messenger RNA and protein suggests the presence of autocrine and paracrine loops. Cancer Res 52: 3213-3219
Supplementary Information accompanies the paper on British Journal of Cancer website (http://www.nature.com/bjc)

Heuchel R, Berg A, Tallquist M, Ahlen K, Reed RK, Rubin K, Claesson-Welsh L, Heldin CH, Soriano P (1999) Platelet-derived growth factor beta receptor regulates interstitial fluid homeostasis through phosphatidylinositol-3' kinase signaling. Proc Natl Acad Sci USA 96: $11410-11415$

Holdhoff M, Kreuzer KA, Appelt C, Scholz R, Na IK, Hildebrandt B, Riess H, Jordan A, Schmidt CA, Van Etten RA, Dorken B, le Coutre P (2005) Imatinib mesylate radiosensitizes human glioblastoma cells through inhibition of platelet-derived growth factor receptor. Blood Cells Mol Dis 34: $181-185$

Houghton PJ, Germain GS, Harwood FC, Schuetz JD, Stewart CF, Buchdunger E, Traxler P (2004) Imatinib mesylate is a potent inhibitor of the ABCG2 (BCRP) transporter and reverses resistance to topotecan and SN-38 in vitro. Cancer Res 64: 2333-2337

Hwang RF, Yokoi K, Bucana CD, Tsan R, Killion JJ, Evans DB, Fidler IJ (2003) Inhibition of platelet-derived growth factor receptor phosphorylation by STI571 (Gleevec) reduces growth and metastasis of human pancreatic carcinoma in an orthotopic nude mouse model. Clin Cancer Res 9: $6534-6544$

Joensuu H, Puputti M, Sihto H, Tynninen O, Nupponen NN (2005) Amplification of genes encoding KIT, PDGFRalpha and VEGFR2 receptor tyrosine kinases is frequent in glioblastoma multiforme. J Pathol 207: 224-231

Kaba SE, Kyritsis AP, Hess K, Yung WK, Mercier R, Dakhil S, Jaeckle KA, Levin VA (1997) TPDC-FuHu chemotherapy for the treatment of recurrent metastatic brain tumors. J Clin Oncol 15: $1063-1070$

Kilic T, Alberta JA, Zdunek PR, Acar M, Iannarelli P, O'Reilly T, Buchdunger E, Black PM, Stiles CD (2000) Intracranial inhibition of platelet-derived growth factor-mediated glioblastoma cell growth by an orally active kinase inhibitor of the 2-phenylaminopyrimidine class. Cancer Res 60: $5143-5150$

Kyritsis AP, Yung WK, Jaeckle KA, Bruner J, Gleason MJ, Ictech SE, Flowers A, Levin VA (1996) Combination of 6-thioguanine, procarbazine, lomustine, and hydroxyurea for patients with recurrent malignant gliomas. Neurosurgery 39: $921-926$

Lamborn KR, Yung WK, Chang SM, Wen PY, Cloughesy TF, Deangelis LM, Robins HI, Lieberman FS, Fine HA, Fink KL, Junck L, Abrey L, Gilbert MR, Mehta M, Kuhn JG, Aldape KD, Hibberts J, Peterson PM, Prados MD (2008) Progression-free survival: an important end point in evaluating therapy for recurrent high-grade gliomas. Neuro Oncol 10: 162-170

Levin VA, Prados MD (1992) Treatment of recurrent gliomas and metastatic brain tumors with a polydrug protocol designed to combat nitrosourea resistance. J Clin Oncol 10: 766-771

Lokker NA, Sullivan CM, Hollenbach SJ, Israel MA, Giese NA (2002) Platelet-derived growth factor (PDGF) autocrine signaling regulates survival and mitogenic pathways in glioblastoma cells: evidence that the novel PDGF-C and PDGF-D ligands may play a role in the development of brain tumors. Cancer Res 62: 3729-3735

Macdonald DR, Cascino TL, Schold Jr SC, Cairncross JG (1990) Response criteria for phase II studies of supratentorial malignant glioma. J Clin Oncol 8: $1277-1280$

Nister M, Libermann TA, Betsholtz C, Pettersson M, Claesson-Welsh L, Heldin CH, Schlessinger J, Westermark B (1988) Expression of messenger RNAs for platelet-derived growth factor and transforming growth factor-alpha and their receptors in human malignant glioma cell lines. Cancer Res 48: 3910 -3918

Ostman A (2004) PDGF receptors-mediators of autocrine tumor growth and regulators of tumor vasculature and stroma. Cytokine Growth Factor Rev 15: $275-286$

Ozvegy-Laczka C, Hegedus T, Varady G, Ujhelly O, Schuetz JD, Varadi A, Keri G, Orfi L, Nemet K, Sarkadi B (2004) High-affinity interaction of tyrosine kinase inhibitors with the ABCG2 multidrug transporter. $\mathrm{Mol}$ Pharmacol 65: $1485-1495$

Parise RA, Ramanathan RK, Hayes MJ, Egorin MJ (2003) Liquid chromatographic-mass spectrometric assay for quantitation of imatinib and its main metabolite (CGP 74588) in plasma. J Chromatogr B Analyt Technol Biomed Life Sci 791: 39-44 
Pietras K, Hanahan D (2005) A multitargeted, metronomic, and maximumtolerated dose 'chemo-switch' regimen is antiangiogenic, producing objective responses and survival benefit in a mouse model of cancer. J Clin Oncol 23: 939-952

Pietras K, Ostman A, Sjoquist M, Buchdunger E, Reed RK, Heldin CH, Rubin K (2001) Inhibition of platelet-derived growth factor receptors reduces interstitial hypertension and increases transcapillary transport in tumors. Cancer Res 61: 2929-2934

Pietras K, Rubin K, Sjoblom T, Buchdunger E, Sjoquist M, Heldin CH, Ostman A (2002) Inhibition of PDGF receptor signaling in tumor stroma enhances antitumor effect of chemotherapy. Cancer Res 62: 5476-5484

Pietras K, Stumm M, Hubert M, Buchdunger E, Rubin K, Heldin CH, McSheehy P, Wartmann M, Ostman A (2003) STI571 enhances the therapeutic index of epothilone B by a tumor-selective increase of drug uptake. Clin Cancer Res 9: 3779-3787

Prados MD, Larson DA, Lamborn K, McDermott MW, Sneed PK, Wara WM, Chang SM, Mack EE, Krouwer HG, Chandler KL, Warnick RE, Davis RL, Rabbitt JE, Malec M, Levin VA, Gutin PH, Phillips TL, Wilson CB (1998) Radiation therapy and hydroxyurea followed by the combination of 6-thioguanine and BCNU for the treatment of primary malignant brain tumors. Int J Radiat Oncol Biol Phys 40: 57-63

Raymond E, Brandes AA, Dittrich C, Fumoleau P, Coudert B, Clement PM, Frenay M, Rampling R, Stupp R, Kros JM, Heinrich MC, Gorlia T, Lacombe D, van den Bent MJ (2008) Phase II study of imatinib in patients with recurrent gliomas of various histologies: a European Organisation for Research and Treatment of Cancer Brain Tumor Group Study. J Clin Oncol 26: 4659-4665

Reardon DA, Egorin MJ, Quinn JA, Rich Sr JN, Gururangan I, Vredenburgh JJ, Desjardins A, Sathornsumetee S, Provenzale JM, Herndon II JE, Dowell JM, Badruddoja MA, McLendon RE, Lagattuta TF, Kicielinski KP, Dresemann G, Sampson JH, Friedman AH, Salvado AJ, Friedman HS (2005) Phase II study of imatinib mesylate plus hydroxyurea in adults with recurrent glioblastoma multiforme. J Clin Oncol 23: 9359-9368
Russell JS, Brady K, Burgan WE, Cerra MA, Oswald KA, Camphausen K, Tofilon PJ (2003) Gleevec-mediated inhibition of Rad51 expression and enhancement of tumor cell radiosensitivity. Cancer Res 63: $7377-7383$

Stupp R, Mason WP, van den Bent MJ, Weller M, Fisher B, Taphoorn MJ, Belanger K, Brandes AA, Marosi C, Bogdahn U, Curschmann J, Janzer RC, Ludwin SK, Gorlia T, Allgeier A, Lacombe D, Cairncross JG, Eisenhauer E, Mirimanoff RO (2005) Radiotherapy plus concomitant and adjuvant temozolomide for glioblastoma. $N$ Engl J Med 352: 987 - 996

Uehara H, Kim SJ, Karashima T, Shepherd DL, Fan D, Tsan R, Killion JJ, Logothetis C, Mathew P, Fidler IJ (2003) Effects of blocking plateletderived growth factor-receptor signaling in a mouse model of experimental prostate cancer bone metastases. J Natl Cancer Inst 95: 458-470

Vredenburgh JJ, Desjardins A, Herndon II JE, Marcello J, Reardon DA, Quinn JA, Rich JN, Sathornsumetee S, Gururangan S, Sampson J, Wagner M, Bailey L, Bigner DD, Friedman AH, Friedman HS (2007) Bevacizumab plus irinotecan in recurrent glioblastoma multiforme. J Clin Oncol 25: $4722-4729$

Wen PY, Yung WK, Lamborn KR, Dahia PL, Wang Y, Peng B, Abrey LE, Raizer J, Cloughesy TF, Fink K, Gilbert M, Chang S, Junck L, Schiff D, Lieberman F, Fine HA, Mehta M, Robins HI, DeAngelis LM, Groves MD, Puduvalli VK, Levin V, Conrad C, Maher EA, Aldape K, Hayes M, Letvak L, Egorin MJ, Capdeville R, Kaplan R, Murgo AJ, Stiles C, Prados MD (2006) Phase I/II study of imatinib mesylate for recurrent malignant gliomas: North American Brain Tumor Consortium Study 99-08. Clin Cancer Res 12: 4899-4907

Went PT, Dirnhofer S, Bundi M, Mirlacher M, Schraml P, Mangialaio S, Dimitrijevic S, Kononen J, Lugli A, Simon R, Sauter G (2004) Prevalence of KIT expression in human tumors. J Clin Oncol 22: 4514-4522

Wong ET, Hess KR, Gleason MJ, Jaeckle KA, Kyritsis AP, Prados MD, Levin VA, Yung WK (1999) Outcomes and prognostic factors in recurrent glioma patients enrolled onto phase II clinical trials. J Clin Oncol 17: $2572-2578$ 